This document was prepared in conjunction with work accomplished under Contract No. DE-AC09-96SR18500 with the U.S. Department of Energy.

This work was prepared under an agreement with and funded by the U.S. Government. Neither the U. S. Government or its employees, nor any of its contractors, subcontractors or their employees, makes any express or implied: 1 . warranty or assumes any legal liability for the accuracy, completeness, or for the use or results of such use of any information, product, or process disclosed; or 2 . representation that such use or results of such use would not infringe privately owned rights; or 3 . endorsement or recommendation of any specifically identified commercial product, process, or service. Any views and opinions of authors expressed in this work do not necessarily state or reflect those of the United States Government, or its contractors, or subcontractors. 


\title{
HEADSPACE GAS EVALUATION OF WELDED PLUTONIUM STORAGE CONTAINERS
}

\author{
Bruce J. Hardy, Stephen P. Harris, Matthew J. Arnold and Stephen J. Hensel \\ Savannah River National Laboratory \\ Aiken, SC 29808
}

\begin{abstract}
The Can Puncture Device (CPD) serves as a containment vessel during the puncture of nested 3013 containers as part of surveillance operations in K-Area. The purpose of the CPD sampling process is to determine the original pressure and composition of gasses within the inner 3013 container.
\end{abstract}

The relation between the composition of the gas sample drawn from the CPD and that originally in the inner 3013 container depends on the degree of mixing that occurs over the interval of time from the puncture to drawing the sample. Gas mixing is bounded by the extremes of no mixing of gases in the inner container and that of complete mixing, in which case the entire CPD system is of uniform composition. Models relating the sample composition and pressure to the initial (pre-puncture) inner can composition and pressure for each of these extremes were developed. Predictions from both models were compared to data from characterization experiments. In the comparison, it was found that the model that assumed complete gas mixing after puncture, the Uniform Mixing Model, showed significantly better agreement with the data than the model that assumed no change in the composition of the inner container, referred to as the Non-Uniform Mixing Model.

Both models were implemented as Microsoft ${ }^{\circledR}$ Excel spreadsheet calculations, which utilize macros, to include the effects of uncertainties and biases in the measurements of process parameters and in the models. Potential inleakage of gas from the glovebox is also addressed. The spreadsheet utilizing the Uniform Mixing Model, which was validated by data from the characterization tests, is used to evaluate the pre-puncture composition and pressure within the inner 3013 container. This spreadsheet model is called the Gas Evaluation Software Tool (GEST).

\section{INTRODUCTION}

Part of the surveillance operations in K-Area involves estimating the composition and quantity of gasses contained within the inner 3013 container. Sampling is performed by puncturing the inner 3013 container in the Can Puncture Device (CPD), which provides a robust containment for puncturing 3013 containers. The CPD is designed to ASME Section VIII standards with a design pressure of $700 \mathrm{psig}$ and is contained within a glove box.

In the sampling process, the 3013 assembly is placed in the CPD, which is then sealed. The pressure within the CPD is measured continuously throughout the sampling process. The CPD/3013 system is purged with nitrogen and evacuated and the outer 3013 container is punctured. After puncture of the outer container, the vacuum and purge process is repeated several times. During the purge and evacuation process a sample is drawn to obtain the gas composition in the CPD system prior to puncture of the inner 3013 container. A schematic of the system is shown in Figures 1 and 2. After the purge/evacuation process, there is a 10 minute leak check before puncturing the inner 3013 container. During this period gas leakage into the CPD from the glove box may occur. The amount of inleakage, if any, is measured from the transient increase in pressure within the CPD system. After the leak check is complete the inner container is punctured, discharging the gasses within to the volume between the inner and outer containers and to the volume between the outer container and the CPD. After waiting for 4 minutes to allow the gasses to distribute throughout the system, a valve connected to the purge cylinder, located downstream of the sample cylinder, is opened. This ensures the gasses in the CPD are pulled close to the sample cylinder inlet valve, see Figure 1. A sample of gas is then drawn from the CPD to be analyzed for composition. Any gas that leaks into the CPD from the glove box, between the time the inner 3013 container is punctured and the time the sample is drawn, is accounted for over the corresponding time interval. The typical pressure trend of the evacuation, inleakage measurement, puncture and sampling process are shown in Figures 3 and 4.

The purpose of the CPD sampling process is to determine the pressure and composition of gaseous species originally present within the inner container. For this reason, it would be ideal if:

1. The CPD system was completely evacuated before the inner 3013 container was punctured.

2. No inleakage occurred.

3. The post-puncture sample was drawn after the system had come to equilibrium, in which case there would be a homogeneous composition of gasses throughout.

Unfortunately, the volumes external to the inner container are not completely evacuated and there is the potential for inleakage from the glove box to the CPD. Further, the discharge of gasses from the inner container will not immediately yield a homogenous composition throughout the system.

The actual transport of gasses and the transfer of thermal energy following puncture of the inner 3013 container is extremely complex. Immediately after the puncture event, the pressure will rapidly equilibrate and individual gas species will be quickly transported by convection from the inner container to Volumes 2 and 3 of Figure 2. In the absence of other factors, the gas composition becomes homogeneous through diffusion, which is a slower process than the rapid mixing that transpires just after the inner container is punctured. The transport process is further complicated by agitation resulting from the rotating drill bit. 
One extreme of the post-puncture mixing process is the case of no change in composition of gaseous species in the inner container. The opposite extreme is the complete mixing of the system, in which the gaseous composition of all volumes is identical after puncture of the inner container. Because the actual state of mixing in the system will lie between these extremes, both were incorporated into separate models that related the gas compositions of the samples to that originally in the inner 3013 container.

\section{MODEL DESCRIPTION}

A model, called the Gas Evaluation Software Tool (GEST), was developed to relate measured pressures and sample compositions from the CPD to the original (pre-puncture) pressure and composition of the inner 3013 container. The model consists of nominal calculations and a statistical analysis that is applied to the values computed by the nominal model. The nominal model predicts the pre-puncture composition and pressure in the inner 3013 container based on measurements made during the surveillance and the statistical analysis applies linear propagation of errors to the pressure and composition model, with a correction for nonlinear effects, to estimate the variance and bias associated with the measured data and the physical assumptions underlying the model. GEST has the ability to analyze six gases: $\mathrm{N}_{2}, \mathrm{O}_{2}, \mathrm{H}_{2}, \mathrm{He}, \mathrm{CH}_{4}$ and $\mathrm{CO}_{2}$ and to address gas inleakage to the CPD from the glovebox over the interval of time between the end of the purge process following puncture of the outer 3013 container and the puncture of the inner 3013 container.

\section{Nominal Model}

Two mixing models were considered for the CPD system. In one model, called the Uniform Mixing Model, it is assumed all gasses mix completely after puncture of the inner 3013 container. The postpuncture gas temperature throughout the system is the weighted average of the gas temperatures prior to the puncture, combined with that of the inleaking gas. Assumptions made for the Uniform Mixing Model are as follows.

Before puncture of the inner 3013 container, it is assumed that:

1. $\mathrm{T}_{\mathrm{CPD} 0}=\mathrm{T}_{\text {outer 0 }}=\mathrm{T}_{\text {glovebox }}$.

2. Gas leaking into the CPD is uniformly mixed over the combined volume between the outer 3013 container and the CPD and in the volume between the inner and outer 3013 containers.

3. The gas in all regions may contain nitrogen, oxygen, hydrogen, helium, methane and carbon dioxide.

After puncture of the inner 3013 container, it is further assumed that:

4. The gas temperature in all volumes is the same and is the result of homogeneous mixing of gasses in all volumes plus the gas that leaks into the CPD over the specified leak time, $\Delta \mathrm{t}_{\text {Leak }}$.

5. The gaseous composition of all volumes is the same and is the result of the homogeneous mixing of gasses in all volumes plus the gas that leaks into the CPD over the specified leak time, $\Delta \mathrm{t}_{\text {Leak }}$.

6. The gasses undergo adiabatic mixing within the CPD system. That is, the stored thermal energy contained in solids and heat transfer out of the system is neglected.

In the second model, called the Non-Uniform Mixing Model, it is assumed that the composition of gasses in the inner 3013 container remain at their pre-puncture composition when the samples are drawn from the CPD. In the Non-Uniform Mixing Model, the post-puncture temperature of gas in the inner 3013 container was assumed to remain at its pre-puncture value. In volumes 2 and 3 of Figure 2, the postpuncture temperature of the gas was the weighted average of the gas originally in these volumes, the gas expelled from the inner 3013 container and the gas leaking into the CPD. The post-puncture conditions assumed for the Non-Uniform Mixing Model are:

1. The gas temperature of the inner 3013 container remains constant at its initial value.

2. The gas temperature in the volume bounded by the inner and outer 3013 containers and in the volume bounded by the outer 3013 container and the CPD, is obtained from the First Law of Thermodynamics for an ideal mixing process.

3. The composition of the inner 3013 container remains fixed.

4. All gas released from the inner 3013 container homogeneously mixes with gas in the volume bounded by the inner and outer 3013 containers (Volume 2 of Figure 2). That mixed gas is then released to the CPD (Volume 3 of Figure 2).

5. The final composition of gas in the volume bounded by the outer 3013 container and the CPD (Volume 3 of Figure 2) results from mixing the gas originally in that volume with the gas composition released from the volume bounded by the inner and outer 3013 containers (Volume 2 of Figure 2) and the gas leaking into the CPD.

6. Gas inleakage to the CPD is from the glove box atmosphere and occurs at a constant rate.

7. The gasses are ideal.

For both the Uniform Mixing Model and the Non-Uniform Mixing Model, pre-puncture compositions and pressures are calculated by simultaneously solving a set of governing equations given in Appendices A1 and A2.

\section{Statistical Analysis}

The statistical analysis within GEST estimates the variance and bias in the predicted compositions and pressure within the inner container arising from error in the measured variables, as well as from differences between actual and assumed physical processes. Both linear propagation of errors and a correction for non-linear effects is included. Details of the statistical model are given in Appendix A3.

\section{COMPARISON WITH DATA}

The CPD analyses models were validated by comparing them to data from characterization experiments. In the experiments, an inner and outer 3013 container were placed in the CPD and, with the outer container already punctured. The pressure and composition of the gas in the CPD was measured and the inner container was punctured. The resulting pressure was recorded and the gas composition was measured by drawing a sample from the CPD. The tests were applied to an inner 3013 container having known volume, pressure and composition. The pressures in the CPD, before and after puncture, were measured. The composition of gas samples taken during the tests were recorded for each sample.

The difference between model prediction and data for the Uniform and Non-Uniform Mixing Models are shown in Figures 5-8. In these figures a value of zero indicates a perfect match with data. The comparison clearly shows that the Uniform Mixing Model provides the best prediction of system performance. Therefore, the Uniform Mixing Model was selected for use as a tool to analyze the CPD sample data and was incorporated into GEST.

A comparison between measured initial (pre-puncture) gas compositions in the inner 3013 container and predictions made by the Uniform Mixing Model are shown in Figures 9 and 10. 


\section{CONCLUSIONS}

Through GEST, pressure and gas composition data taken from the CPD can be used to estimate the original pressure and gaseous composition within the inner 3013 container. GEST also calculates biases and variances based on the biases and variances of input parameters and the predictive model itself. If data is available, GEST can also address the effect of covariances between input parameters on the variance of predicted quantities

In a comparison between initial compositions within the inner 3013 container predicted by GEST and known values from controlled experiments, it was found that the Uniform Mixing Model was far superior to the Non-Uniform Mixing Model. It was thus inferred that the underlying assumptions for the Uniform Mixing Model were more representative of actual CPD system behavior. Hence, the version of GEST based on the Uniform Mixing Model was selected for interpretation of CPD data.

\section{REFERENCES}

Sonntag, R. E., Borgnakke, C., and Van Wylen, G. J., "Fundamentals of Thermodynamics," $6{ }^{\text {th }}$ Ed. ,Wiley, New York, 2002. 
FIGURES

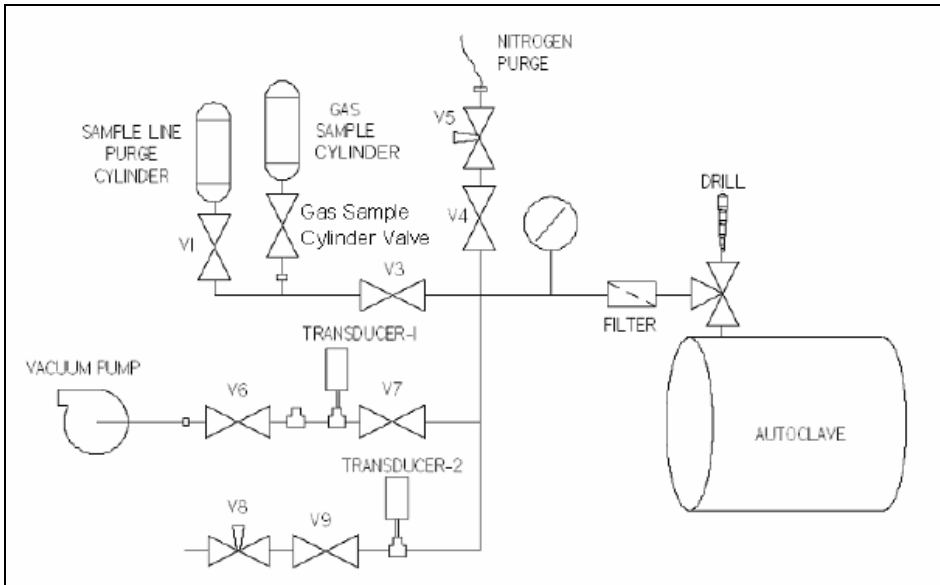

Figure 1 CPD system layout.

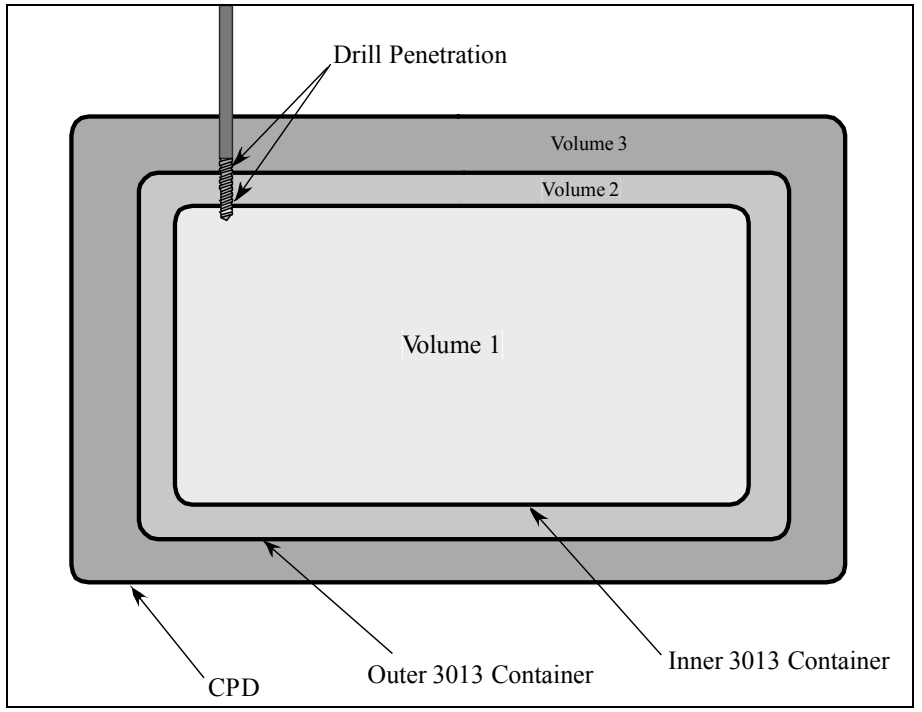

Figure 2 Schematic of the CPD system.

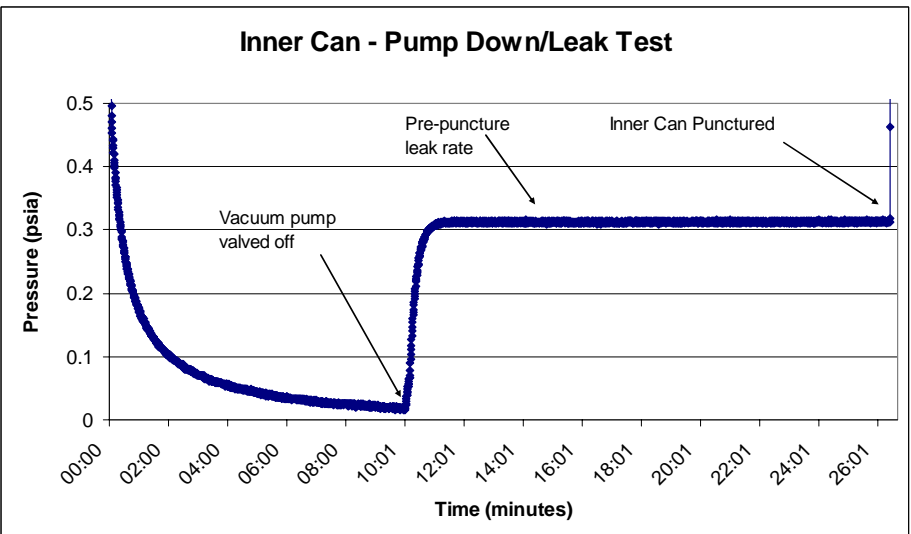

Figure 3 Inner can evacuation and inleakage test period.

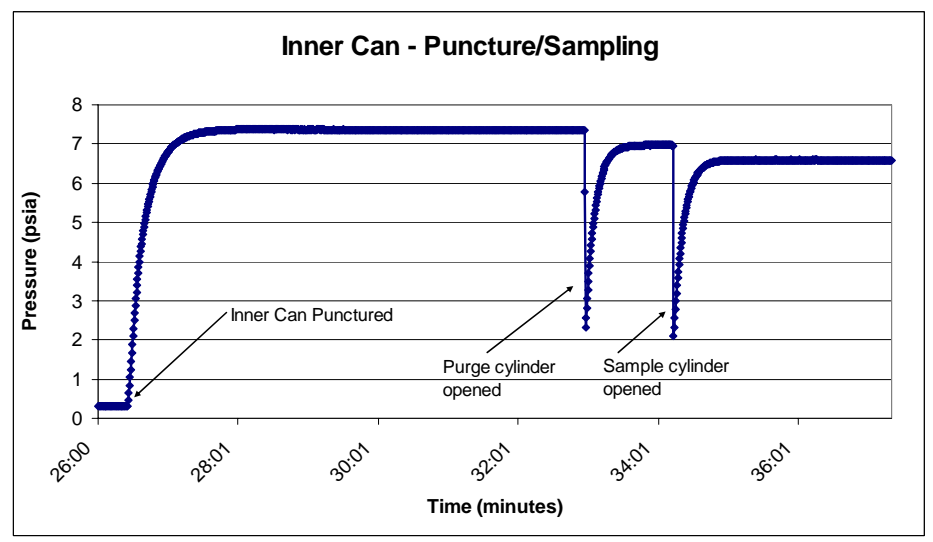

Figure 4 Inner can puncture and sampling process.

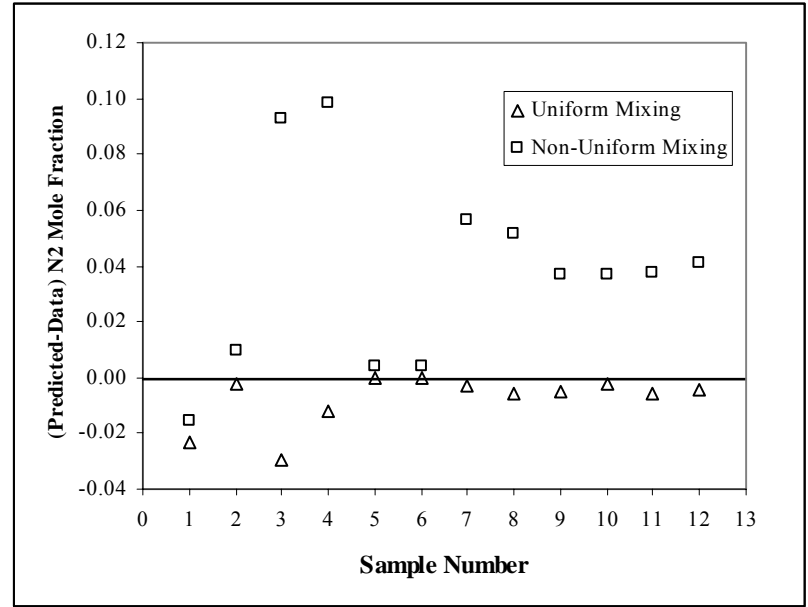

Figure 5 Difference between predicted and measured $\mathrm{N}_{2}$ mole fraction in the CPD after puncture of the inner 3013 container.

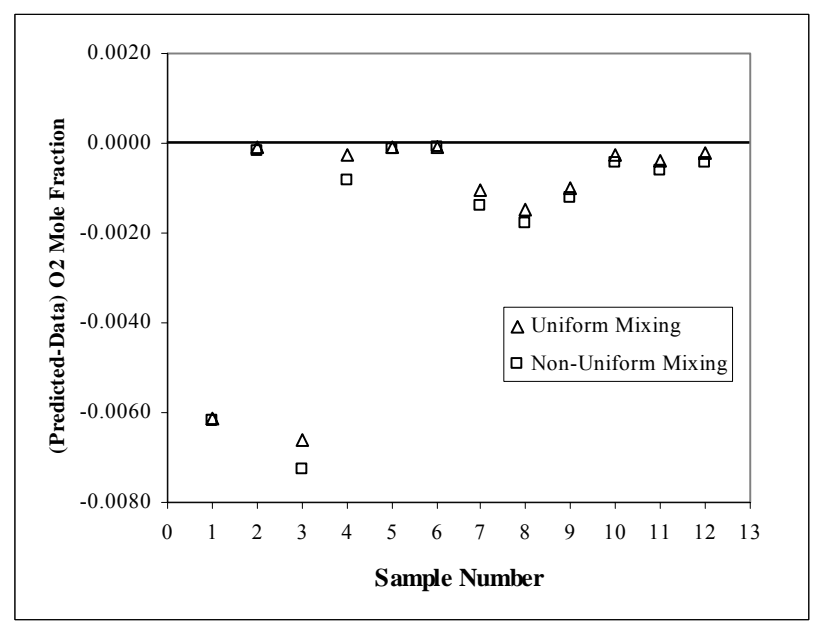

Figure 6 Difference between predicted and measured $\mathrm{O}_{2}$ mole fraction in the CPD after puncture of the inner 3013 container. 
WSRC-STI-2008-00216

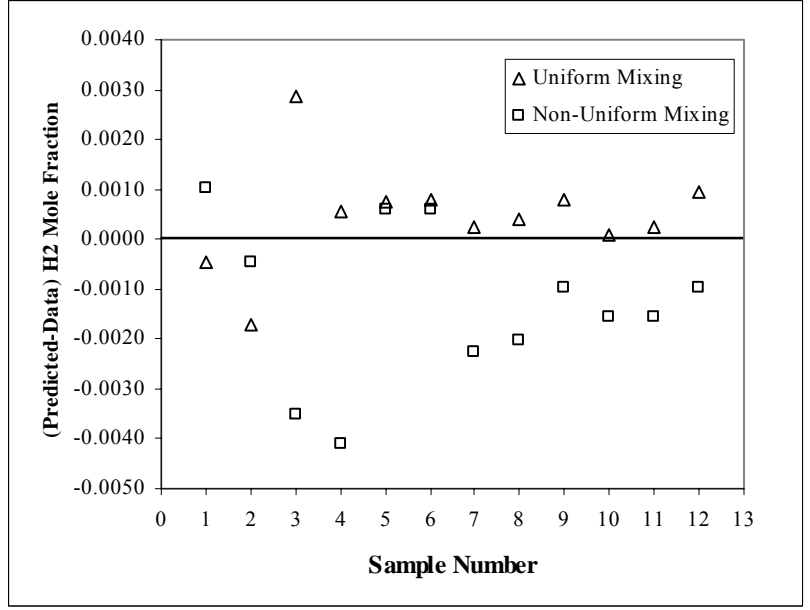

Figure 7 Difference between predicted and measured $\mathrm{H}_{2}$ mole fraction in the CPD after puncture of the inner 3013 container.

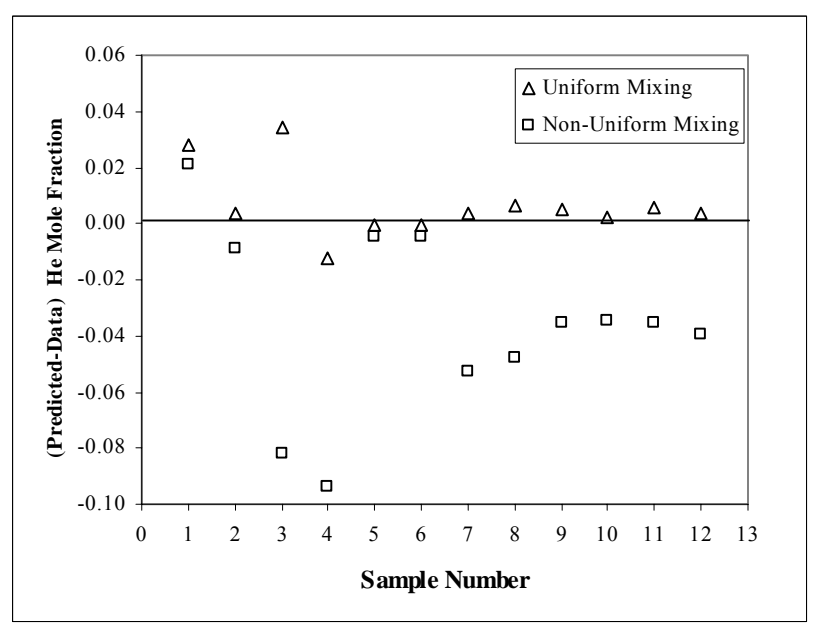

Figure 8 Difference between predicted and measured $\mathrm{He}$ mole fraction in the CPD after puncture of the inner 3013 container.

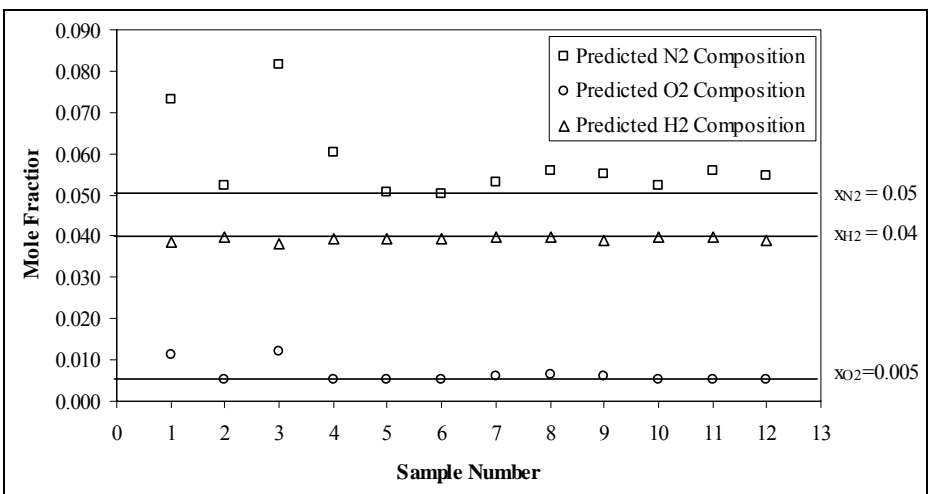

Figure 9 Pre-puncture $\mathrm{N}_{2}, \mathrm{O}_{2}$ and $\mathrm{H}_{2}$ mole fractions in the inner 3013 container, as predicted by the Uniform Mixing model for the characterization test data. The actual prepuncture mole fractions for these species are shown by the solid lines, the values of which are given next to the right side of the plot.

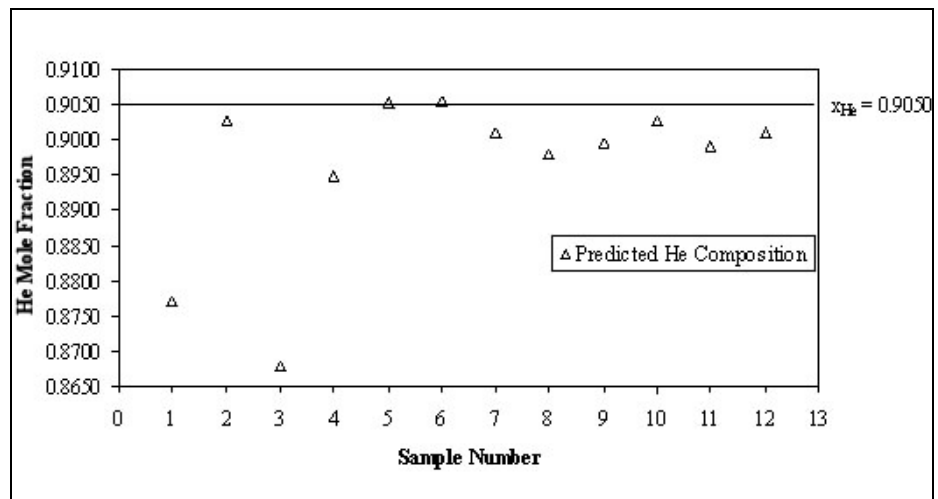

Figure 10 Pre-puncture $\mathrm{He}$ mole fractions in the inner 3013 container, as predicted by the Uniform Mixing model for the characterization test data. The actual pre-puncture mole fraction for He is shown by the solid line and the values is given next to the right side of the plot. 


\section{APPENDIX}

\section{A1 Governing Equations for Uniform Mixing Model}

Prior to puncture of the inner 3013 container, the Uniform Mixing Model assumes that the outer 3013 container has been punctured and that in the volume bounded by the inner and outer 3013 containers and in the volume bounded by the outer 3013 container and the $\mathrm{CPD}$, the gas composition and temperature are uniform and equal.

Before puncture of the inner 3013 container, it is assumed that:

1. $\mathrm{T}_{\mathrm{CPD} 0}=\mathrm{T}_{\text {outer } 0}=\mathrm{T}_{\text {glovebox }}$.

2. Gas leaking into the CPD is uniformly mixed over the combined volume between the outer 3013 container and the CPD and in the volume between the inner and outer 3013 containers.

3. The gas in all regions may contain nitrogen, oxygen, hydrogen, helium, methane and carbon dioxide. that:

After puncture of the inner 3013 container, it is further assumed

4. The gas temperature in all volumes is the same and is the result of homogeneous mixing of gasses in all volumes plus the gas that leaks into the CPD over the specified leak time, $\Delta \mathrm{t}_{\text {Leak }}$.

5. The gaseous composition of all volumes is the same and is the result of the homogeneous mixing of gasses in all volumes plus the gas that leaks into the CPD over the specified leak time, $\Delta \mathrm{t}_{\text {Leak }}$.

6. The gasses undergo adiabatic mixing within the CPD system. That is, the stored thermal energy contained in solids and heat transfer out of the system is neglected.

By Assumption 4, after puncture the gas temperature in all volumes is the mixture temperature $\bar{T}_{U}$, the uniform model mixture temperature, in $(\mathrm{K})$.

Because the final gas composition and temperatures are the same throughout the system, this representation is referred to as the uniform mixing model.

By Assumption 1, after puncture the gas temperature in all volumes is the mixture temperature $\overline{\mathrm{T}}_{\mathrm{U}}$, the uniform model mixture temperature, in $(\mathrm{K})$.

The total number of moles of gas in the volume between the outer 3013 container and the CPD before puncture is given by

$\mathrm{n}_{\mathrm{CPD} 0}=\left(\mathrm{P}_{0}+\left.\Delta \mathrm{t}_{\text {Leak BP }} \frac{\partial \mathrm{P}}{\partial \mathrm{t}}\right|_{\text {Leak BP }}\right) \frac{\mathrm{V}_{\mathrm{CPD}}}{\mathrm{RT}_{\mathrm{CPD} 0}}$.

The total number of moles of gas in the volume between the inner and outer 3013 containers before puncture is given by

$\mathrm{n}_{\text {outer 0 }}=\left(\mathrm{P}_{0}+\left.\Delta \mathrm{t}_{\text {Leak BP }} \frac{\partial \mathrm{P}}{\partial \mathrm{t}}\right|_{\text {Leak BP }}\right) \frac{\mathrm{V}_{\text {outer }}}{\mathrm{RT}_{\text {outer } 0}}$.

The mole fraction of gaseous species $\mathrm{i}$ in the inner 3013 container before puncture is given by

$\mathrm{x}_{\mathrm{i} \text { i inner } 0}=\frac{\left[\begin{array}{l}\mathrm{x}_{\mathrm{i} F}\left(\mathrm{n}_{\text {inner } 0}+\mathrm{n}_{\text {outer } 0}+\mathrm{n}_{\text {CPD } 0}+\mathrm{n}_{\text {Leak }}\right) \\ -\left(\mathrm{n}_{\mathrm{i} \text { outer } 0}+\mathrm{n}_{\mathrm{i} \text { CPD } 0}+\mathrm{n}_{\mathrm{i} \text { Leak }}\right)\end{array}\right]}{\mathrm{n}_{\text {inner } 0}}$
The mole fraction of gaseous species $i$ in the volume between the inner and outer 3013 containers before puncture of the inner 3013 container is given by

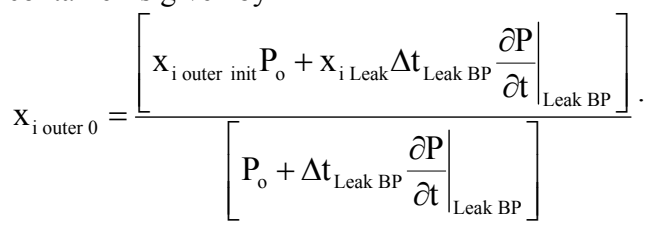

The number of moles of gaseous species $i$ in the volume between the inner and outer 3013 containers, before puncture of the inner 3013 container, is given by Eq. A1.5. This value includes pre-puncture inleakage.

$\mathrm{n}_{\mathrm{i} \text { outer } 0}=\mathrm{x}_{\mathrm{i} \text { outer } 0} \mathrm{n}_{\text {outer } 0}$

The mole fraction of gaseous species $i$ in the volume between the outer 3013 container and the CPD before puncture of the inner container after pre-puncture inleakage occurs, is given by

$\mathrm{x}_{\mathrm{i} \text { CPD } 0}=\frac{\left[\mathrm{x}_{\mathrm{i} \text { CPD init }} \mathrm{P}_{\mathrm{o}}+\left.\mathrm{x}_{\mathrm{i} \mathrm{Leak}} \Delta \mathrm{t}_{\text {Leak BP }} \frac{\partial \mathrm{P}}{\partial \mathrm{t}}\right|_{\text {Leak BP }}\right]}{\left[\mathrm{P}_{\mathrm{o}}+\left.\Delta \mathrm{t}_{\text {Leak BP }} \frac{\partial \mathrm{P}}{\partial \mathrm{t}}\right|_{\text {Leak BP }}\right]}$

A1.6

The number of moles of gaseous species $i$ in the volume between the outer 3013 container and the CPD, before puncture of the inner 3013 container, is given by Eq. A1.7. This value includes prepuncture inleakage.

$\mathrm{n}_{\mathrm{i} \text { CPD } 0}=\mathrm{x}_{\mathrm{i} \text { CPD } 0} \mathrm{n}_{\mathrm{CPD} 0}$

The number of moles of gaseous species $\mathrm{i}$ in that leak into the CPD system over the interval of time $\Delta t_{\text {eak }}$ is

$\mathrm{n}_{\mathrm{i} \text { Leak }}=\mathrm{x}_{\mathrm{i} \text { Leak }} \mathrm{n}_{\text {Leak }}$

The temperature, $\overline{\mathrm{T}}_{\mathrm{U}}$, of the gas mixture in the uniform system is

$\overline{\mathrm{T}}_{\mathrm{U}}=\frac{\mathrm{P}_{\mathrm{F}} \mathrm{V}_{\mathrm{T}}}{\mathrm{R}\left(\mathrm{n}_{\text {inner } 0}+\mathrm{n}_{\mathrm{CPD} 0}+\mathrm{n}_{\text {outer } 0}\right)}$.

The number of moles of gas that leak into the CPD system over the interval of time $\Delta \mathrm{t}_{\text {Leak }}$ after puncture of the inner 3013 container is

$\mathrm{n}_{\text {Leak }}=\frac{\left.\Delta \mathrm{t}_{\text {Leak }} \frac{\mathrm{dP}}{\mathrm{dt}}\right|_{\text {Leak }}\left(\mathrm{n}_{\text {inner 0 }}+\mathrm{n}_{\text {CPD 0 }}+\mathrm{n}_{\text {outer 0 }}\right)}{\mathrm{P}_{\mathrm{F}}}$.

From equations A1.1, A1.2, A1.4 through A1.6, A1.9 and A.10 it can be seen that the energy balance before and after puncture, in terms of the constant volume specific heat, is a function of $\mathrm{n}_{\text {inner } 0}$ alone.

Hence, the energy balance may be used as an objective function to solve for $\mathrm{n}_{\text {inner } 0}$. Once $\mathrm{n}_{\text {inner } 0}$ is determined, $\overline{\mathrm{T}}_{\mathrm{U}}, \mathrm{n}_{\text {Leak }}$ and $\mathrm{x}_{\mathrm{i} \text { inner } 0}$ can be obtained directly from Equations A1.9, A1.10, and A1.3, respectively. The temperature dependent constant volume specific heats for each species were obtained from Sonntag, Borgnakke and Van Wylen [2002]. 


\section{A.2 Governing Equations for Non-Uniform Mixing Model}

Prior to puncture of the inner 3013 container, the Non-Uniform Mixing Model assumes that the outer 3013 container has been punctured and that in the volume bounded by the inner and outer 3013 containers and in the volume bounded by the outer 3013 container and the $\mathrm{CPD}$, the gas composition and temperature are uniform and equal.

After puncture of the inner 3013 container, it is assumed that:

1. The gas temperature of the inner 3013 container remains constant at its initial value.

2. The gas temperature in the volume bounded by the inner and outer 3013 containers and in the volume bounded by the outer 3013 container and the CPD, is obtained from the First Law of Thermodynamics for an ideal mixing process.

3. The composition of the inner 3013 container remains fixed.

4. All gas released from the inner 3013 container homogeneously mixes with gas in the volume bounded by the inner and outer 3013 containers (Volume 2 of Figure 2). That mixed gas is then released to the CPD (Volume 3 of Figure 2).

5. The final composition of gas in the volume bounded by the outer 3013 container and the CPD (Volume 3 of Figure 2) results from mixing the gas originally in that volume with the gas composition released from the volume bounded by the inner and outer 3013 containers (Volume 2 of Figure 2) and the gas leaking into the CPD.

6. Gas inleakage to the CPD is from the glove box atmosphere and occurs at a constant rate.

7. The gases are ideal.

Because the final gas composition and temperatures vary within the system, this representation is referred to as the non-uniform mixing model.

The post-puncture mole balance for the region between the inner and outer 3013 containers is

$\mathrm{n}_{\text {outer } \mathrm{F}}=\frac{\left(\mathrm{P}_{\mathrm{F}}+\left.\Delta \mathrm{t}_{\text {Leak }} \frac{\partial \mathrm{P}}{\partial \mathrm{t}}\right|_{\text {Leak }}\right)}{\mathrm{R}} \frac{\mathrm{V}_{\text {outer }}}{\overline{\mathrm{T}}}$

The post-puncture mole balance for the region between the outer 3013 container and the CPD is

$\mathrm{n}_{\mathrm{CPD} F}=\frac{\left(\mathrm{P}_{\mathrm{F}}+\left.\Delta \mathrm{t}_{\text {Leak }} \frac{\partial \mathrm{P}}{\partial \mathrm{t}}\right|_{\text {Leak }}\right)}{\mathrm{R}} \frac{\mathrm{V}_{\mathrm{CPD}}}{\overline{\mathrm{T}}}$

The mole fraction of gaseous species $i$ in the inner 3013 container before puncture is

$\mathrm{x}_{\mathrm{i} \text { outer F }}=\frac{\mathrm{n}_{\mathrm{i} \text { CPD F }}-\mathrm{n}_{\mathrm{i} \text { CPD } 0}-\left(\mathrm{x}_{\mathrm{i}} \mathrm{n}\right)_{\text {Leak }}}{\left(\mathrm{n}_{\text {outer } 0}+\mathrm{n}_{\text {inner } 0}-\mathrm{n}_{\text {inner F }}-\mathrm{n}_{\text {outer F }}\right)}$

The number of moles of gaseous species $\mathrm{i}$ in the volume between the outer 3013 container and CPD after puncture of the inner 3013 container is

$$
\begin{aligned}
\mathrm{n}_{\mathrm{i} \text { CPD F }}= & \frac{\left\{\begin{array}{l}
{\left[\mathrm{x}_{\mathrm{i} \text { inner } 0}\left(\mathrm{n}_{\text {inner } 0}-\mathrm{n}_{\text {inner } \mathrm{F}}\right)+\mathrm{n}_{\mathrm{i} \text { outer } 0}\right\rfloor} \\
\times\left(\mathrm{n}_{\text {outer } 0}+\mathrm{n}_{\text {inner } 0}-\mathrm{n}_{\text {inner F }}-\mathrm{n}_{\text {outer F }}\right)
\end{array}\right\}}{\left(\mathrm{n}_{\text {inner } 0}-\mathrm{n}_{\text {inner } \mathrm{F}}+\mathrm{n}_{\text {outer } 0}\right)} \\
& +\mathrm{n}_{\mathrm{i} \text { CPD } 0}+\left(\mathrm{x}_{\mathrm{i}} \mathrm{n}\right)_{\text {Leak }}
\end{aligned}
$$

The mole fraction of gaseous species $i$ in the inner container is given by Eq. A2.5. By Assumption 3 this value is fixed for the nonuniform mixing model.

$$
\begin{aligned}
\mathrm{x}_{\mathrm{i} \text { inner }}= & \frac{\left\{\begin{array}{l}
\left(\mathrm{n}_{\mathrm{i} \text { CPD F }}-\mathrm{n}_{\mathrm{i} \text { CPD } 0}-\left(\mathrm{x}_{\mathrm{i}} \mathrm{n}\right)_{\text {Leak }}\right) \\
\times\left(\mathrm{n}_{\text {inner } 0}-\mathrm{n}_{\text {inner F }}+\mathrm{n}_{\text {outer } 0}\right)
\end{array}\right\}}{\left(\mathrm{n}_{\text {outer } 0}+\mathrm{n}_{\text {inner } 0}-\mathrm{n}_{\text {inner F }}-\mathrm{n}_{\text {outer F }}\right)\left(\mathrm{n}_{\text {inner } 0}-\mathrm{n}_{\text {inner F }}\right)} \\
& -\frac{\mathrm{n}_{\text {i outer } 0}}{\left(\mathrm{n}_{\text {inner } 0}-\mathrm{n}_{\text {inner F }}\right)}
\end{aligned}
$$

The number of moles of gaseous species i in the volume between the outer 3013 container and CPD, after puncture of the inner 3013 container, may also be written as

$\mathrm{n}_{\mathrm{i} \text { CPD F }}=\mathrm{x}_{\mathrm{i} \text { CPD F}} \mathrm{n}_{\mathrm{CPD} \mathrm{F}}$

The post-puncture temperature of the gas mixture outside the inner 3013 container is

$\overline{\mathrm{T}}=\frac{\mathrm{P}_{\mathrm{F}} \mathrm{V}}{\mathrm{R}\left(\Delta \mathrm{n}_{\text {inner }}+\mathrm{n}_{\mathrm{CPD} 0}+\mathrm{n}_{\text {outer } 0}\right)}$

The number of moles of gas that leak into the CPD system over the interval of time $\Delta \mathrm{t}_{\text {Leak }}$, is

$\mathrm{n}_{\text {Leak }}=\frac{\left.\Delta \mathrm{t}_{\text {Leak }} \frac{\mathrm{dP}}{\mathrm{dt}}\right|_{\text {Leak }}\left(\Delta \mathrm{n}_{\text {inner }}+\mathrm{n}_{\text {CPD 0 }}+\mathrm{n}_{\text {outer 0 }}\right)}{\mathrm{P}_{\mathrm{F}}}$

The mole fraction of gaseous species $\mathrm{i}$ in the inner 3013 container before puncture is

$$
\begin{aligned}
\mathrm{x}_{\mathrm{i} \text { inner }}= & \frac{\left(\mathrm{n}_{\mathrm{i} \text { CPD F }}-\mathrm{n}_{\mathrm{i} \text { CPD } 0}-\left(\mathrm{x}_{\mathrm{i}} \mathrm{n}\right)_{\text {Leak }}\right)\left(\Delta \mathrm{n}_{\text {inner }}+\mathrm{n}_{\text {outer } 0}\right)}{\left(\mathrm{n}_{\text {outer } 0}-\mathrm{n}_{\text {outer F }}+\Delta \mathrm{n}_{\text {inner }}\right) \Delta \mathrm{n}_{\text {inner }}} \\
& -\frac{\mathrm{n}_{\mathrm{i} \text { outer } 0}}{\left(\Delta \mathrm{n}_{\text {inner }}\right)}
\end{aligned}
$$

From equations A2.7, A2.8 and A2.9 it can be seen that the energy balance on volumes outside the inner 3013 container, before and after puncture, in terms of the constant volume specific heat, is a function of $\Delta \mathrm{n}_{\text {inner }}$ alone. Hence, the energy balance may be used as an objective function to solve for $\Delta \mathrm{n}_{\text {inner }}$. Once $\Delta \mathrm{n}_{\text {inner }}$ is determined, $\overline{\mathrm{T}}, \mathrm{n}_{\text {Leak }}$ and $\mathrm{x}_{\mathrm{i} \text { inner }}$ can be obtained directly from Equations A2.7, A2.8, and A2.9, respectively. The temperature dependent constant volume specific heats for each species were obtained from Sonntag, Borgnakke and Van Wylen [2002].

Finally, $\mathrm{n}_{\text {inner } 0}$ can be calculated as 


$$
\begin{aligned}
\mathrm{n}_{\text {inner } 0} & =\Delta \mathrm{n}_{\text {inner }}+\mathrm{n}_{\text {inner } \mathrm{F}} \\
& =\Delta \mathrm{n}_{\text {inner }}+\frac{\left(\mathrm{P}_{\mathrm{F}}+\left.\Delta \mathrm{t}_{\text {Leak }} \frac{\partial \mathrm{P}}{\partial \mathrm{t}}\right|_{\text {Leak }}\right)}{\mathrm{R}} \frac{\mathrm{V}_{\text {inner }}}{\mathrm{T}_{\text {inner }}}
\end{aligned}
$$

\section{A3 Statistical Model}

The system model predicts the initial composition and pressure in the inner 3013 container based on certain physical assumptions. However, the input parameters used by the model, as well as the assumed physical behavior of the system immediately following the puncture of the inner 3013 container, are subject to error. The error may take the form of instrument uncertainty and bias, systematic error in the taking of samples, deviation from the assumed physics underlying the puncture event and a number of other sources. For this reason it is necessary to estimate the error in the estimate of the composition and pressure within the inner 3013 container.

The statistical model used in the spreadsheets is based on a propagation of error technique for a functional of random variables. Let $f$ denote the "true" value of a pre-puncture mole fraction or pressure within the inner 3013 container an let $\mathrm{p}$ denote the value derived by GEST from the "true" values, $\xi$, of parameters. Write

$\mathrm{f}=\mathrm{p}(\underline{\xi})+\sum_{\mathrm{k}=1}^{\mathrm{m}} \varepsilon_{\mathrm{k}}$

where: $\varepsilon_{\mathrm{k}}=$ Errors associated with the GEST model.

Within its radius of convergence, we may write

$\mathrm{f}(\underline{\xi})=\mathrm{p}\left(\underline{\xi}_{0}\right)+\sum_{\mathrm{i}=1}^{\mathrm{n}}\left[\left.\frac{\partial \mathrm{p}}{\partial \xi_{\mathrm{i}}}\right|_{\underline{\xi}_{0}}\left(\xi_{\mathrm{i}}-\xi_{\mathrm{i} 0}\right)+\mathrm{O}\left(\xi_{\mathrm{i}}^{2}\right)\right]+\sum_{\mathrm{k}=1}^{\mathrm{m}} \varepsilon_{\mathrm{k}}$

where: $\underline{\xi}_{0}=\left(\xi_{10}, \xi_{20}, \xi_{30}, \cdots, \xi_{n 0}\right)=$ Measured values of parameters.

The higher order terms in equation A.2-1 denote non-linear effects.

If $\mathrm{f}$ is a one-to-one function, then neglecting higher order terms, and applying the averaging operator, yields an expression for mean value of $f,\langle f(\underline{\xi})\rangle$, as

$\langle\mathrm{f}(\underline{\xi})\rangle=\mathrm{f}\left(\underline{\xi}_{0}\right)+\left.\sum_{\mathrm{i}=1}^{\mathrm{n}} \frac{\partial \mathrm{p}}{\partial \xi_{\mathrm{i}}}\right|_{\underline{\xi}_{0}}\left(\left\langle\xi_{\mathrm{i}}\right\rangle-\xi_{\mathrm{i} 0}\right)+\left\langle\mathrm{O}\left(\underline{\xi}^{2}\right)\right\rangle+\sum_{\mathrm{k}=1}^{\mathrm{m}}\left\langle\varepsilon_{\mathrm{k}}\right\rangle$

where: \langle\rangle denotes the averaging operator.

Equation A3.3 relates the mean value of $f$ to its value at nominal parameter values, $\mathrm{f}\left(\underline{\xi}_{0}\right)$. Thus, Equation A3.3 can be used to calculate the bias, $\beta$, between the mean and nominal value of $f$ as $\beta=($ bias in functional $)=\langle\mathrm{f}(\underline{\xi})\rangle-\mathrm{f}\left(\underline{\xi}_{0}\right)$

$=\left.\sum_{\mathrm{i}=1}^{\mathrm{n}} \frac{\partial \mathrm{p}}{\partial \xi_{\mathrm{i}}}\right|_{\underline{\xi}_{0}}\left(\left\langle\xi_{\mathrm{i}}\right\rangle-\xi_{\mathrm{i} 0}\right)+\left\langle\mathrm{O}\left(\underline{\xi^{2}}\right)\right\rangle+\sum_{\mathrm{k}=1}^{\mathrm{m}}\left\langle\varepsilon_{\mathrm{k}}\right\rangle$
Physically, the bias is the correction from the nominal prediction of $\mathrm{f}$ to the mean of $f$.

Neglecting higher order terms in Equation A3.4 gives an approximation for the bias in terms of linear propagation of errors

$$
\beta=\langle\mathrm{f}(\underline{\xi})\rangle-\left.\mathrm{f}\left(\underline{\xi}_{0}\right) \approx \sum_{\mathrm{i}=1}^{\mathrm{n}} \frac{\partial \mathrm{p}}{\partial \xi_{\mathrm{i}}}\right|_{\underline{\xi}_{0}} \beta_{\mathrm{i}}+\sum_{\mathrm{k}=1}^{\mathrm{m}}\left\langle\varepsilon_{\mathrm{k}}\right\rangle
$$

where: $\beta_{\mathrm{i}}=\left\langle\xi_{\mathrm{i}}\right\rangle-\xi_{\mathrm{i} 0}=($ bias in variable $\mathrm{i})$.

In terms of Equation A3.5 and Equation A3.2, with second and higher order terms neglected, the variance of $\mathrm{f}, \sigma_{\mathrm{f}}{ }^{2}$, via linear propagation of errors is

$$
\begin{aligned}
\sigma_{\mathrm{f}}{ }^{2}= & \left\langle(\mathrm{f}(\underline{\xi})-\langle\mathrm{f}(\underline{\xi})\rangle)^{2}\right\rangle \\
\approx & \sum_{\mathrm{k}=1}^{\mathrm{m}} \sigma_{\varepsilon_{\mathrm{k}}}^{2}+\sum_{\substack { \mathrm{k}=1 \\
\begin{subarray}{c}{\mathrm{~s} \neq=1 \\
\mathrm{~s} \neq \mathrm{k}{ \mathrm { k } = 1 \\
\begin{subarray} { c } { \mathrm { s } \neq = 1 \\
\mathrm { s } \neq \mathrm { k } } }\end{subarray}}^{\mathrm{m}} \rho_{\varepsilon_{\mathrm{k}} \varepsilon_{\mathrm{s}}} \sigma_{\varepsilon_{\mathrm{k}}} \sigma_{\varepsilon_{\mathrm{s}}}+\left.2 \sum_{\mathrm{k}=1}^{\mathrm{m}} \sum_{\mathrm{i}=1}^{\mathrm{n}} \frac{\partial \mathrm{p}}{\partial \xi_{\mathrm{i}}}\right|_{\underline{\xi}_{0}} \rho_{\varepsilon_{\mathrm{k}} \mathrm{i}} \sigma_{\varepsilon_{\mathrm{k}}} \sigma_{\xi_{\mathrm{i}}} \\
& +\sum_{\mathrm{i}}^{\mathrm{n}}\left(\left.\frac{\partial \mathrm{p}}{\partial \xi_{\mathrm{i}}}\right|_{\underline{\xi}_{0}}\right)^{2} \sigma_{\xi_{\mathrm{i}}}^{2}+\left.\left.\sum_{\mathrm{j}=1}^{\mathrm{n}} \sum_{\substack{\mathrm{i}=1 \\
\mathrm{i} \neq \mathrm{j}}}^{\mathrm{n}} \frac{\partial \mathrm{p}}{\partial \xi_{\mathrm{j}}}\right|_{\underline{\xi}_{0}} \frac{\partial \mathrm{p}}{\partial \xi_{\mathrm{i}}}\right|_{\underline{\xi}_{0}} \rho_{\mathrm{ji}} \sigma_{\xi_{\mathrm{j}}} \sigma_{\xi_{\mathrm{i}}}
\end{aligned}
$$

where: $\quad \rho_{\mathrm{ji}}=$ The correlation coefficient of $\xi_{\mathrm{j}}$ and $\xi_{\mathrm{i}}$

$$
=\frac{\operatorname{Cov}\left(\xi_{\mathrm{j}}, \xi_{\mathrm{i}}\right)}{\sigma_{\xi_{\mathrm{j}}} \sigma_{\xi_{\mathrm{i}}}}
$$

$\rho_{\varepsilon_{\mathrm{k}} \mathrm{i}}=$ The correlation coefficient of $\varepsilon_{\mathrm{k}}$ and $\xi_{\mathrm{i}}$

$$
=\frac{\operatorname{Cov}\left(\varepsilon_{\mathrm{k}}, \xi_{\mathrm{i}}\right) \cdot 2-1}{\sigma_{\varepsilon_{\mathrm{k}}} \sigma_{\xi_{\mathrm{i}}}}
$$

$\rho_{\varepsilon_{\mathrm{k}} \varepsilon_{\mathrm{s}}}=$ The correlation coefficient of $\varepsilon_{\mathrm{k}}$ and $\varepsilon_{\mathrm{s}}$

$$
=\frac{\operatorname{Cov}\left(\varepsilon_{\mathrm{k}}, \varepsilon_{\mathrm{s}}\right)}{\sigma_{\varepsilon_{\mathrm{k}}} \sigma_{\varepsilon_{\mathrm{s}}}}
$$

$\operatorname{Cov}(\mathrm{x}, \mathrm{y})=$ The covariance of $\mathrm{x}$ and $\mathrm{y}$ $=\langle(x-\langle x\rangle)(y-\langle y\rangle)\rangle$.

$\sigma_{\xi_{\mathrm{i}}}=$ The standard deviation of $\xi_{\mathrm{i}}$.

$\sigma_{\varepsilon_{\mathrm{i}}}=$ The standard deviation of $\varepsilon_{\mathrm{i}}$.

The contribution of higher order terms to the bias and variance are estimated from a statistical analysis of the model and data and combined as root-mean-squares with the error terms, $\varepsilon_{\mathrm{k}}$, that address the difference between the predictions of the model to the "true" values of the dependent variables (mole fractions and pressures). Although the equations derived in this section can account for the covariance between the $\varepsilon_{\mathrm{k}}$ terms, the covariance between the $\varepsilon_{\mathrm{k}}$ terms and the independent variables $\xi_{\mathrm{i}}$, and the covariance between the independent variables $\xi_{\mathrm{i}}$ and $\xi_{\mathrm{j}}$ for $\mathrm{i} \neq \mathrm{j}$, such covariances are assumed to be zero in the current version of GEST. 